\title{
The Problem Distiller Tool: supporting teachers in uncovering why their students have problems understanding Threshold Concepts
}

\author{
Sara Cruz ${ }^{1}$, José Alberto Lencastre ${ }^{1}$, Clara Coutinho ${ }^{1}$, Gill Clough ${ }^{2}$ and Anne \\ Adams $^{2}$ \\ ${ }^{1}$ Institute of Education, University of Minho, Braga, Portugal \\ sara.acruz@gmail.com, \{jlencastre, \\ ccoutinho\}@ie.uminho.pt \\ ${ }^{2}$ Institute of Educational Technology, Open University, \\ Milton Keynes, United Kingdom \\ \{gill.clough, anne.adms\}@open.ac.uk
}

\begin{abstract}
This study explored the use of a web-based tool entitled 'Problem Distiller' designed to support teachers in uncovering why their students have problems understanding Threshold Concepts. Data collected involved interviews with two math teachers, invited to experiment the Problem Distiller tool and Think Aloud protocol. Content analysis was used to process and analyse the collected data.. Findings show that teachers found it helpful when the information they entered through the Problem Distiller was fed back as they constructed an online diagnostic quiz. Focusing on the teachers' understanding of why the students have problems is an effective way of tackling the barriers posed by Threshold Concepts and can be integrated with existing strategies and teaching approaches.
\end{abstract}

Keywords: Threshold Concepts. Tricky Topics, Technology-Enhanced Learning. Deeper Understanding.

Please cite this article in press as: Cruz, S., Lencastre, J. A., Coutinho, C., Clough, G., \& Adams, A. (2016). The Problem Distiller Tool: supporting teachers in uncovering why their students have problems understanding Threshold Concepts. In Susan Zvacek, James Uhomoibhi, Gennaro Costagliola and Bruce M. McLaren (eds.), CSEDU 2016 Revised Selected Best Papers. Rome: Springer. (in press) 


\section{Introduction}

Threshold Concepts are fundamental topics in education without which students cannot progress in the subject (Cousin, 2006). They frequently contain 'troublesome knowledge' that students struggle to understand, sometimes taking refuge in memorisation (without understanding). Threshold Concepts can be so hard to comprehend that they can create in students a state of anxiety and confusion (Meyer $\&$ Land 2006), and lead them to fail or give up a subject altogether (Machiocha, 2014). Although Threshold Concepts have been identified in different disciplines, these topics are particularly common in STEM - Science, Technology, Engineering and Mathematics -, and they are often the reason that leads the students to give up studying subjects in these areas.

How to identify a Threshold Concept and distinguish them from other learning topics has provoked debate between academics. According to Meyer and Land (2003), a concept is likely to be threshold if it has one or more of the following criteria:

- Transformative - once understood, it potentially causes a significant shift in the perception of a subject (or part thereof); sometimes it may even transform one's personal identity.

- Irreversible - it is unlikely that a Threshold Concept is forgotten or unlearned once acquired due to transformation.

- Integrative - a Threshold Concept is able to expose "the previously hidden interrelatedness of something".

- Bounded - a Threshold Concept can have borders with other Threshold Concept which help to define disciplinary areas.

- Troublesome - they may be counter-intuitive (common sense understanding vs. expert understanding).

It is unclear how many of these five characteristics are required to define a concept as a Threshold Concept. Nevertheless, the authors emphasize that once understood the Threshold Concept allows the student to be able to solve problems with degree of advanced difficulty (Meyer, Knight, Callaghan, \& Baldock, 2015).

Thus, enabling the student to comprehend a Threshold Concept is a concern for any teacher. Understanding the causes of the students' difficulty helps the teacher to help them and also to adopt appropriate teaching strategies to support the student in overcoming these difficulties.

In this paper we review the JuxtaLearn Problem Distiller, a tool designed to support teachers in uncovering why their students have problems understanding Threshold Concepts. The tool displays a set of tabbed panes "prompting teachers to reflect on and select possible reasons why their students might be having a particular problem, connecting all the information entered to the appropriate tricky topic and stumbling block or blocks" (Adams \& Clough, 2015, p. 6). In the JuxtaLearn project "Tricky Topic' was the name we use to refer to the Threshold Concepts identified by the teacher in their practice with students. For a deeper understanding of this approach see: "Threshold Concepts Vs. Tricky Topics" (Cruz, Lencastre, Coutinho, Clough, \& Adams, 2016). 
In section 2, we present examples of studies with different modes for identifying Threshold Concepts. The Section 3, we present the Problem Distiller Tool, the JuxtaLearn approach to adapt theories of Threshold Concepts into teachers' practices. In Section 4, we present the methods for the data collection and analysis processes. In Section 5 we present our main results and reflections. We conclude in Section 6 with a synthesis and proposals for future work.

\section{Review of studies}

Much academic effort has been devoted to theoretically understanding and identifying Threshold Concepts, but little of this has translated into their practical application in educational settings.

Loertscher, Green, Lewis, Lin and Minderhout (2014) conducted a study involving 75 teachers and 50 students, where involved an iterative process intended to identify threshold concepts in biochemistry. These authors used a process to identify threshold concepts that consists of five phases: (phase 1) pilot student focus group interviews, (phase 2) interdisciplinary life sciences workshop, (phase 3) biochemistry core collaborators workshop and dissemination workshop, (phase 4) student focus group interviews and (phase 5) data analysis and determination of a working list of threshold concepts. Using this process, they were able to identify threshold concepts that are fundamental to the deeper understanding of biochemistry but are also strongly related to fundamental concepts of chemistry and biology.

Meyer, Knight, Callaghan and Baldock (2015) conducted a case study which used a data triangulation approach to identify threshold concepts that students should understand before solving specific problems of a civil engineering course. For collection purposes teachers took part in dialogue on understanding and conceptual capacity enabling learning for all participants in the process. They concluded that involving the various course stakeholders in an analysis about conceptual understanding and capacity makes learning achievable to all process participants. It also provides a basis for pedagogies and evaluations to facilitate advanced results in students.

Barradell and Kennedy-Jones (2013) introduced a conceptual model that integrates three components: the (i) students learning, the (ii) threshold concepts and (iii) curriculum. According to this holistic model, when students talk about the threshold concepts they encounter various ideas. When these ideas are understood as part of a whole, they provide a more systematic way of thinking about how to improve educational practice.

JuxtaLearn approach focuses on adapting theories of Threshold Concepts into teachers' practical application with Tricky Topics, so that they can be integrated with the practice-based approach of teachers.

\section{The Problem Distiller Tool}

Co-developed with teachers, and included in the CLIPIT (Figure 1) - the Web Space for the JuxtaLearn project -, the Tricky Topic Tool (Figure 2) is an "in progress" 
online database with a catalogue of Threshold Concepts and / or Tricky Topics shaped by teachers from their perspective and based on their practice.

After several trials done in the UK and Portugal, the CLIPIT has a database with a lot of Tricky Topics.

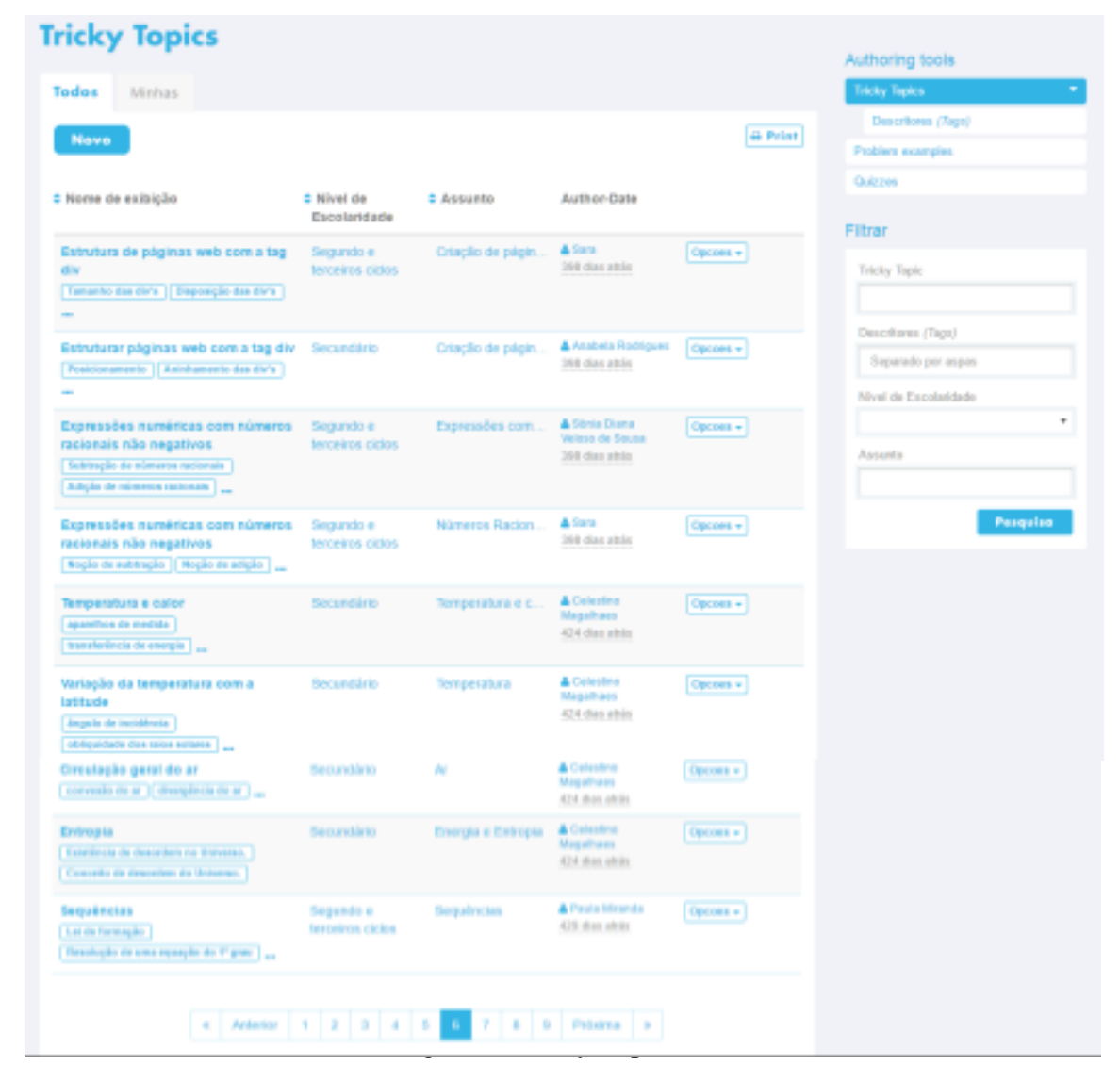

Fig. 1. Tricky Topic list

This list of Threshold Concepts is under construction. If a Threshold Concept does not already exist in the Tricky Topic Tool, added, for example, by another teacher, the teacher can add one that fits their students' learning problems. In order to populate the Tricky Topic Tool the teacher has to enter the name of the Tricky Topic and write a description of the student's specific problem with that topic (Figure 1).

Once the teacher adds the Tricky Topic she/he can link it into some 'Stumbling Blocks', i.e. learning barriers he thinks that the problem can be broken down into and which are commonly found by her/his students, using another feature of the Tricky Topic Tool: The Problem Distiller (Figure 2). It is easy for the teacher to reuse a listed 
concept that has already been identified and added to the Tricky Topic Tool by another teacher and to add, remove or change an already described challenges in the platform for their students.

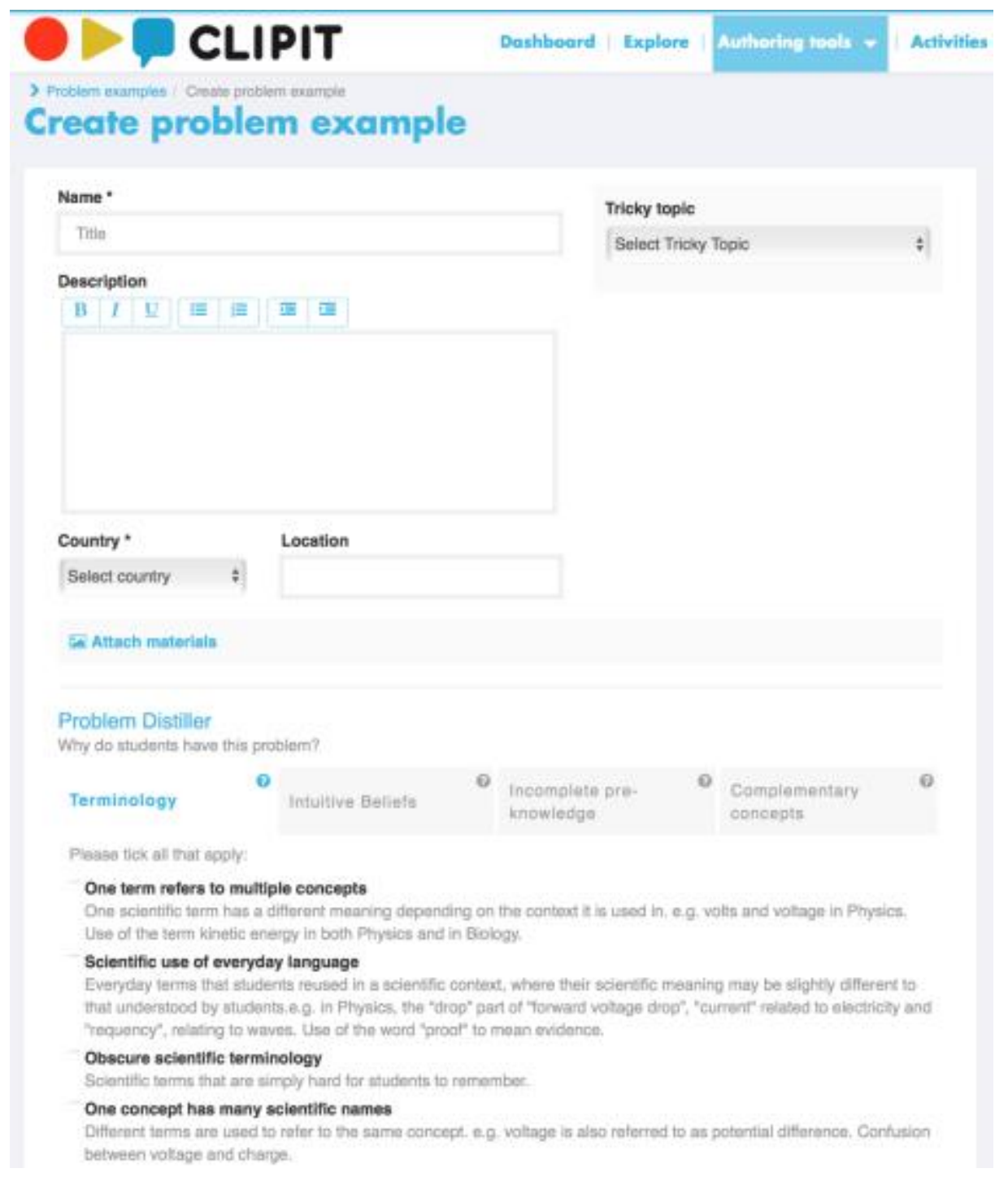

Fig 2. Problem Distiller Tool

The Problem examples are classified using four categories that were obtained during the first cycle of activities - interviews, workshops - conducted with the teachers in the UK during the participatory design of the JuxtaLearn Tricky Topic Tool. These four categories are: 'Terminology', 'Intuitive Beliefs', 'Incomplete pre-knowledge' 
and 'Complementary Concepts'. This information is passed through to the quiz question authoring tool, focusing the question authoring on probing the students' understanding rather than simply mapping directly onto a topic as taught in class (Adam \& Clough, 2015).

The category 'Terminology' refers to the fact that "in all the subjects explored during the interviews and workshops, terminology was a big issue, everyday terms acquiring a different meaning when used as part of a scientific discourse, new scientific terms being introduced, one term meaning different things in different contexts, multiple scientific terms used to refer to the same thing" (JuxtaLearn Project Deliverable Report D2.1 - Taxonomy).

The category 'Intuitive Beliefs' refers to "informal, intuitive ways of thinking about the world which are strongly biased toward causal explanations. In many cases, as students advance in their understanding of science and technology subjects, they need to grasp principles which are fundamentally counter-intuitive. Such barriers can be very difficult to overcome as often the students and teachers do not realise they are there" (JuxtaLearn Project Deliverable Report D2.1 - Taxonomy).

The category 'Incomplete pre-knowledge' refers to situations "Where students either lacked an understanding of, or had an incomplete or flawed understanding of underpinning topics, or scientific method, process or discourse. For example, to understand genetic drift in biology, students need a pre-knowledge of the process of natural selection. Misunderstandings may also occur when teacher and student do not share the same scientific discourse, with students believing they have understood when, in reality, their understanding is based on a misinterpretation of what has been said" (JuxtaLearn Project Deliverable Report D2.1 - Taxonomy).

The category 'Complementary Concepts', refers to "chunks of information that students need to learn alongside the Threshold Concept. They are smaller, effectively 'sub-concepts' that a student needs to understand in order to grasp the overall Threshold Concept. For example, when learning about potential difference in physics, students also need to know about current, volts, voltage and Ohm's law. Sometimes such underpinning pre-knowledge is taught at the same time as the Threshold Concept, sometimes it is assumed that students have learned it already. When an understanding of essential concepts is missing or flawed, this can inhibit understanding of topics that rely on it" (JuxtaLearn Project Deliverable Report D2.1 Taxonomy).

The Problem Distiller quiz creation stage uses the student's problems and their associated Stumbling Blocks as cues to guide the teacher in creating questions that address these specific concerns. The teacher is scaffolded to write questions that specifically target the identified stumbling blocks in order to verify if the student has the difficulties identified for the Threshold Concept. These questions form a diagnostic quiz that is effective at uncovering fundamental misconceptions (Figure 3). The first step when creating a question for the quiz is to select the Tricky Topic and the Stumbling Blocks that the question will target. This step displays all the information related to that question: (1) stumbling blocks, (2) example of the student problems, and (3) suggested causes.For each of the Stumbling Blocks, the teacher has 
to create at least one question so that all the problem areas are covered. As the teacher creates the quiz, s(he) links each question to one or more related Stumbling Blocks (the why factor), selecting the question type - multiple choices, checkboxes, true / false or numeric -, the possible options, and the correct answer. The teacher can also choose the difficulty of the test, include images and videos, and a timeout for the student to perform the quiz. The finished quiz is created and stored CLIPIT and made available for resuse by other teachers.

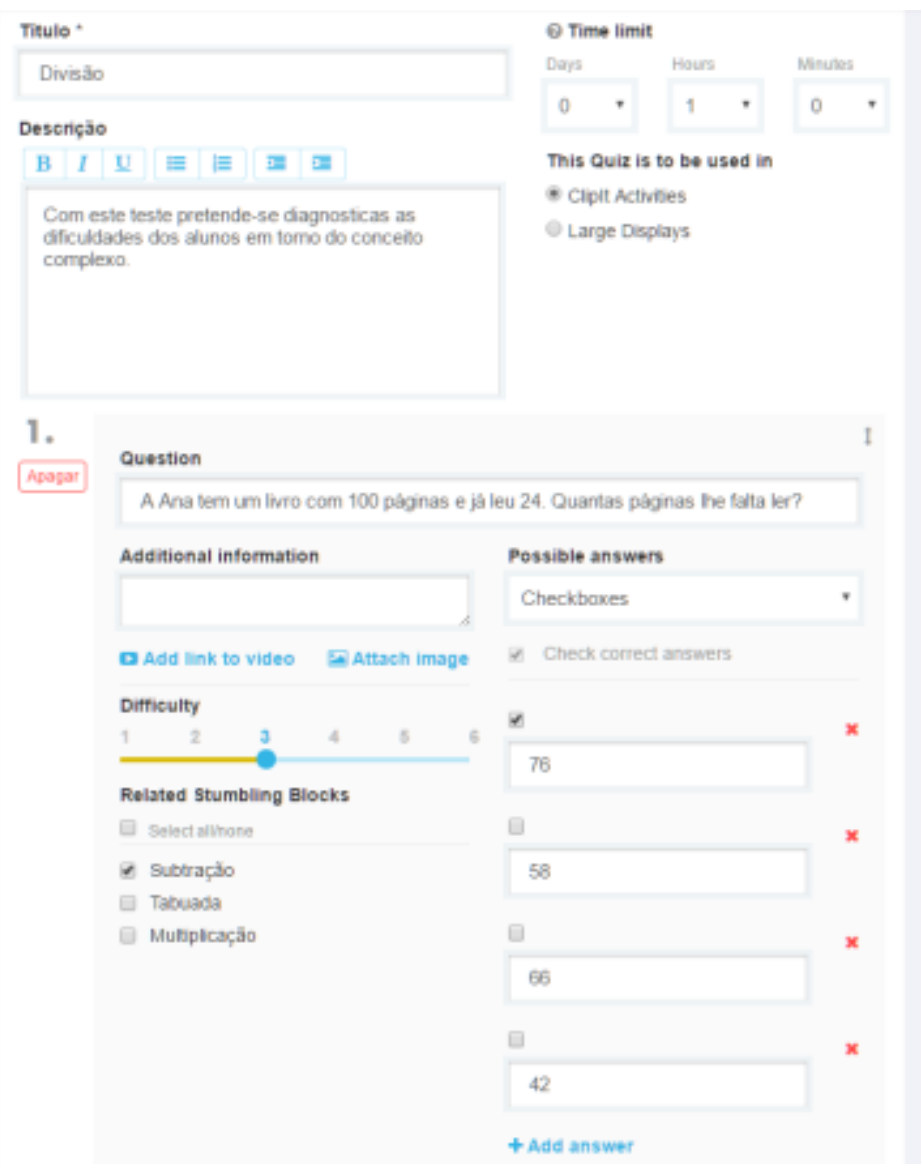

Fig 3.Teacher's interface when designing the questions in the CLIPIT

The connection between the Stumbling Blocks determines the complexity weighting of each question in the quiz and produces a radar chart visualisation for each student who has completed the quiz. This radar chart is a graphical translation of learning analytics and gives the teacher (and the student) a visual analysis of the level of the student's understanding on the Threshold Concept. In the quiz, complex questions can be connected to several Stumbling Blocks, whereas a simple question is connected to 
only one Stumbling Block. When the students take the diagnostic quiz, the visualised results show where the gaps in their knowledge are. The visualisation of the radar chart shows to the student his or her level of understanding of that concept in a form that is easy to understand. (Figure 4).

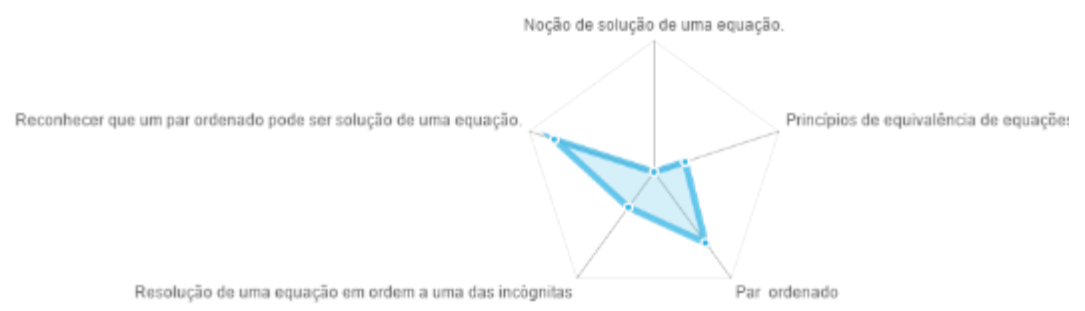

Fig 4. Initial radar chart after performing the diagnostic quiz

This radar chart represents the depth of the students' understanding of the 'Tricky Topic' and its connection with its various obstacles. For teachers, the radar chart flags up areas badly understood by the student, allowing them to adapt their teaching and implement intervention strategies to improve success in students learning. So, based on the diagnostic quiz information, the teacher can set up specific materials to overcome the identified difficulties, propose and differentiated tasks for knowledge consolidation, encourage the student's progress in the areas where(s) he has more difficulties in order to strengthen the understanding of the 'Tricky Topics'.

At the end of the learning process the student may take another quiz on the same Tricky Topic to assess their learning progress.

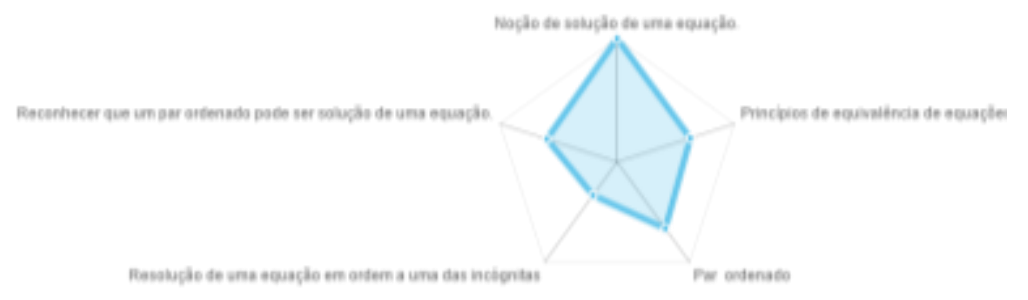

Fig 5. Final radar chart after taking the quiz a second time

If the students take a second diagnostic quiz, after the teacher has worked with them to overcome the weaknesses highlighted by the first diagnostic quiz, both student and teacher can easily see whether their difficulties have been overcome. We see in Figure 5 that the student's understanding of the stumbling blocks, as illustrated by the vertices in the radar chart, has improved. Comparing the post-quiz example shown in Figure 5 to the diagnostic quiz result shown in Figure 4, one stumbling block has been completely overcome, reflecting the fact that that the student answered all the questions related to that problem correctly.

Comparing the diagnostic radar chart and the final radar chart, the teacher can analyse the evolution of student learning. In this case, the understanding of 'Tricky Topics' improved essencially on two of its obstacle levels, the "notion of solution of an 
equation" and the "principles of equation equivalence." While becoming aware of the improvement of the student, the teacher can plan teaching strategies that build deeper knowledge about the concept for the student.

\section{Method}

Data collection involved interviews with two math teachers from Elementary school (5th and 6th grades). The first teacher (T1) is a male, in his fifties, and teaches in a school in Marco de Canaveses, near the city of Porto in the north of Portugal. The other teacher (T2) is a female of forty-six years old, teaching in a school in the city of Braga. Both teachers have worked in teaching their entire working career.

Data was collected through structured interviews (20 minutes each) with the support of the Problem Distiller tool and Think Aloud protocol (Van Someren, Barnard, \& Sandberg, 1994). Based on their teaching practice they identified the math 'Tricky Topics' that were problematic for their students, and checked if the 'Tricky Topics' were already listed in the database (The Tricky Topic Tool). If not, we explained how to generate a new 'Tricky Topic'. Then, with the guidance of the Problem Distiller tool, the teachers divided each 'Tricky Topic' into stumbling blocks, and wrote a brief description of students' specific problems. The aim was to ensure that each interview presented the teachers with exactly the same questions in the same order (the JuxtaLearn taxonomy). This guarantees that answers can be reliably aggregated and that comparisons can be made with confidence between the two teachers.

For the processing and analysis of the obtained data, we performed a content analysis (Bardin, 2013), as it allows for logical deductions based on the data obtained. The teachers' utterances were recorded and transcribed for the analysis. During the process, set of dimensions and categories emerged from data: (i) algorithm, (ii) basic operations, (iii) teaching method in the 1 st level of education, (iv) reasoning and (v) use of the calculator.

It is interesting to notice that dimensions ii and iv are also reported in the literature of 'Division' (Fernandes \& Martins, 2014; Montague, 2003; Zhao, et. al, 2014). In the dimension 'a' (algorithm), we analysed the relationship between the difficulty in the division operation and knowledge that students have of the division algorithm. In this dimension, we represent the speeches of teachers by "T1.a" or "T2.a". In dimension 'o' (operations), we analyse the relationship between the difficulty in the division operation and the students' knowledge of basic operations and we represent the speeches of teachers by "T1.o" or "T2.o". In dimension 'm' (method), we analyse the relationship between the difficulties in operating with diagnosed division in students and the teaching method in the 1 st level of education. In this dimension, we represent the speeches of teachers by "T1.m" or "T2.m". In dimension ' $r$ ' (reasoning), we analyse the relationship between the difficulties in operating with the division and thinking capacity demonstrated by students. In this dimension we represent the speeches of teachers by "T1.r" or "T2.r". In dimension 'c' (calculator), we analyse the relationship between the difficulties in operating with the division and the use of calculators by students. In this dimension, we represent the utterances of teachers by "T1.c" or "T2.c". The utterances were numbered according to their occurrences in the text. 


\subsection{Data collection}

In this section, we describe the use of the Problem Distiller tool with two math teachers we interviewed for our study. We used the tool to help the teachers reflect on the causes of the student problems they had identified. When teachers expressed problems explaining why their students had difficulty understanding the Threshold Concept or 'Tricky Topic', they were guided by the Problem Distiller tool to identify the 'Stumbling Blocks'.

Both teachers said that the Tricky Topic "division operation" is a Threshold Concept, at least for their students. T1 identified the following Stumbling Blocks: (1) organise calculations, (2) adding notion, (3) multiplication and (4) subtraction. After the teacher had reflected on the Threshold Concept through the mind map, he filled the CLIPIT with it. Below we present the mind map (Figure 6) created by this teacher, and the Threshold Concept in the Tricky Topic Tool (Figure 7).

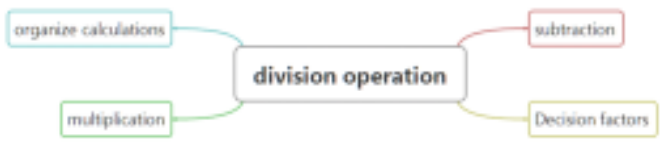

Fig 6. Tricky Topic and their Stumbling blocks to T1.

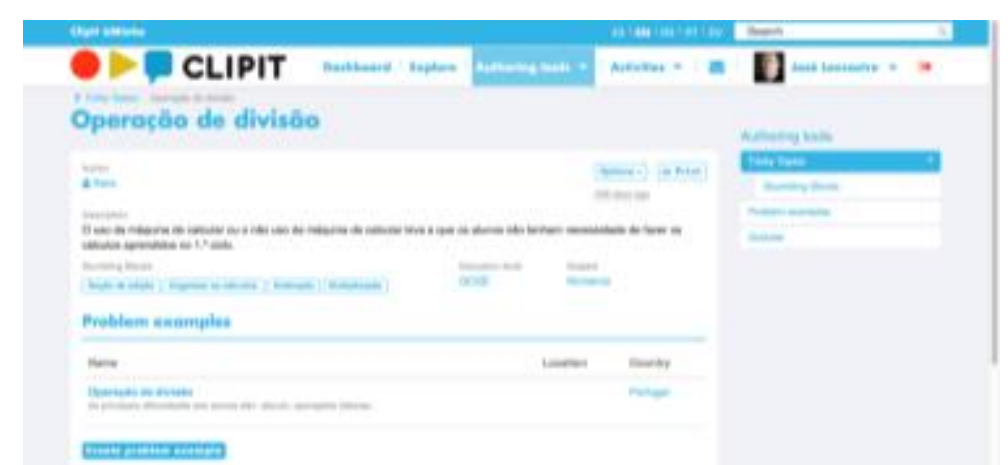

Fig 7.CLIPIT interface where the Threshold Concept and the 'Stumbling Blocks', and also a description of the concept

For the Tricky Topic 'division operation', T2 identified the following Stumbling Blocks: (1) subtraction, (2) multiplication tables and (3) multiplication. Again, after the teacher had reflected on the Threshold Concept through the mind map, populated CLIPIT with it. Below we present a mind map (Figure 8) created by this teacher, and the Threshold Concept in the Tricky Topic Tool (Figure 9). 


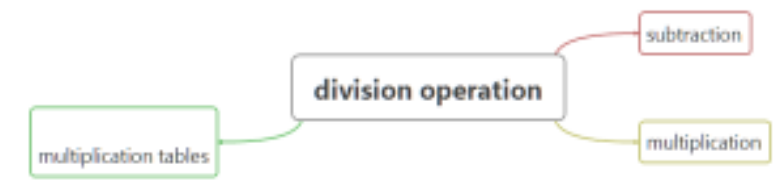

Fig 8: Tricky Topic and their Stumbling blocks to T2

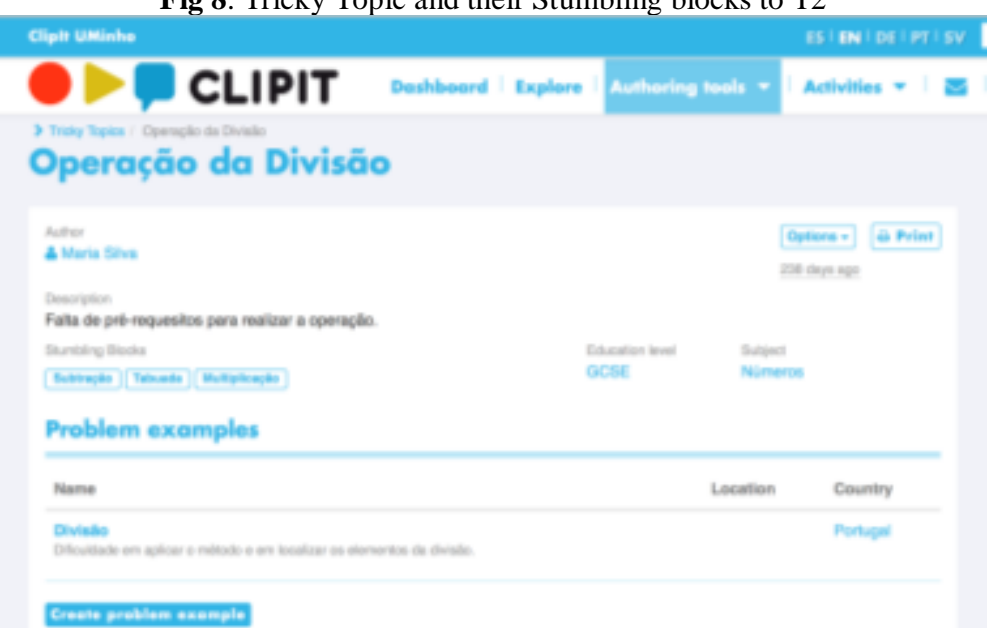

Fig 9. CLIPIT interface where the Threshold Concept and the 'Stumbling Blocks', and also a description of the concept

During the interviews the Problem Distiller tool guided the teacher in identifying the causes of student's misunderstandings, adding particular examples of student's difficulties based on the teachers' experience with former students (Figure 10). 


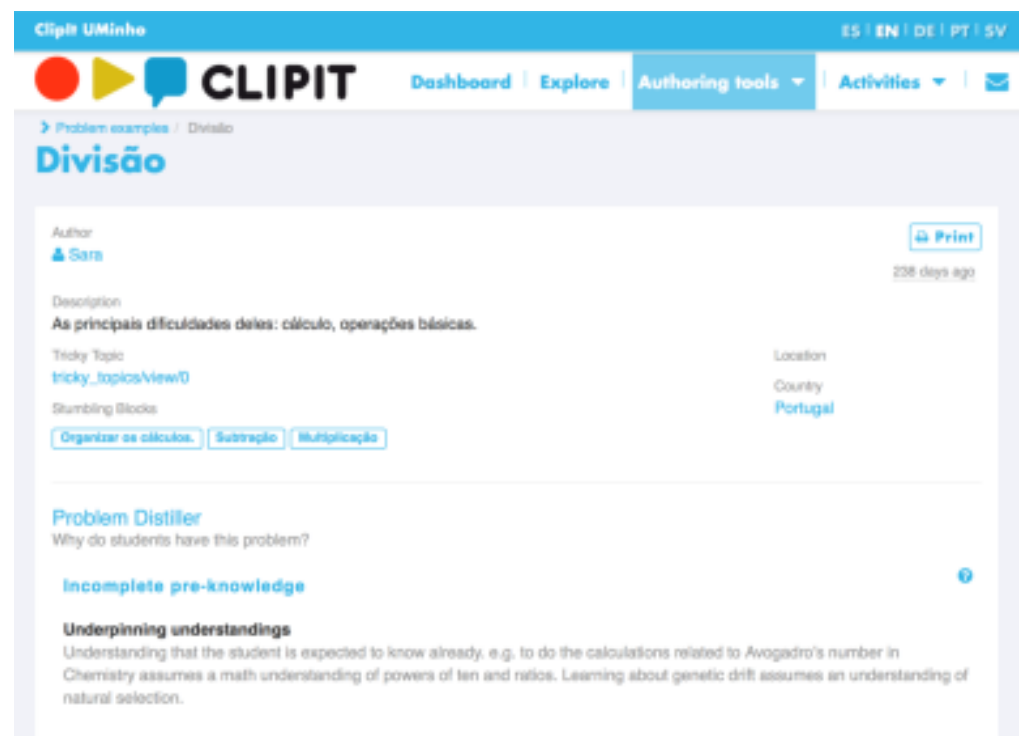

Fig 2. CLIPIT interface: Tricky Topic and the 'Stumbling Blocks'

Once identified the Threshold Concept the first reaction of both teachers (T1 and T2) when we asked them the reasons for these student's difficulties was a profound "silence". Then we showed the teachers the tabs with the following categories: Terminology, Intuitive Beliefs, Incomplete Pre-knowledge, and Complementary Concepts. Thus, we helped them to analyse each of these categories. Regarding the $\mathrm{T} 1$, he selected the "Incomplete pre-knowledge" and the "Underpinning understandings", corresponding to the problem "Understanding what the student is expected to know already. e.g., to do the calculations related to Avogadro's number in Chemistry assume the math understanding of powers of ten and ratios. Learning about genetic drift assumes an understanding of natural selection". Regarding T2, she selected the "Intuitive Beliefs" and the "causal flawed reasoning", corresponding to the problem "Reasoning based on the assumption of goal or purpose, e.g., birds have wings so they can fly. Genes turn off in order to enable the cell to develop properly. Inappropriate assumption of cause and effect, e.g., release an object along a curved path, and it will keep in the curve, rocks are so pointy that animals will not sit on Them and crush Them". This teacher also selected the" Incomplete pre- knowledge "and the" Underpinning understandings "with the same problem of T1.

Thus, one of the teachers (T2) identified in their students two types of problems for the same Threshold Concept, and one of these problems is the same as defined by T1. The Tricky Topic Tool and the Problem Distiller Tool allowed each teacher to see the problems identified by other teachers and thus reflect on the problems of their students compared to others.

As they made selections from the Problem Distiller Tool, teachers were identifying problems that students typically encounter in understanding the 'concept of division' 
and were also able to reflect on why these problems occur and how they can might be solved in the classroom with proper teaching and learning interventions.

For a deeper analysis on the teacher's utterances (Think Aloud protocol), we prepared a content analysis. The content analysis was developed according to the phases suggested by Bardin (2013). Table 1 presents teachers' utterances according to five categories considered in the analysis.

Table 1. Category of analysis

\begin{tabular}{|c|c|c|}
\hline $\begin{array}{c}\text { Category of } \\
\text { analysis }\end{array}$ & $\mathrm{N}$ & Evidences \\
\hline Algorithm & 6 & $\begin{array}{l}\text { "Students do not know the algorithm implementation rules and do } \\
\text { not know how to decompose a number" (T1.a1) } \\
\text { "The Euclidean algorithm requires students to do successive } \\
\text { divisions. The difficulties for them are huge. They can apply the } \\
\text { algorithm realize the algorithm because it forces you to do } \\
\text { successive divisions" (T1.a2) } \\
\text { "In the division operation, students have many difficulties, mainly } \\
\text { because most students cannot understand the division by two } \\
\text { numbers" (T1.a3). } \\
\text { "Students have difficulty in applying the divide operation algorithm } \\
\text { and the location of elements: divider, rest, quotient and divisor" } \\
\text { (T2.a1). } \\
\text { "In the algorithm, students also have difficulty in organizing values } \\
\text { in the process of division" (T2.a2). } \\
\text { "Difficulty in organizing calculations when they are split"(T2.a3). }\end{array}$ \\
\hline $\begin{array}{c}\text { Basic } \\
\text { Operations }\end{array}$ & 5 & $\begin{array}{l}\text { "Students have more difficulties in what we call the basic } \\
\text { prerequisites, this is, the level of basic operations: addition, } \\
\text { subtraction, multiplication and division. Of these four operations, } \\
\text { where they appear the greatest difficulties is the division" (T1.o1) } \\
\text { "the main difficulties of them: calculation, basic operations. We } \\
\text { may say so, students know add, they know subtract, but if we } \\
\text { multiply there are already great difficulties. If we are talking in the } \\
\text { room, mainly by two numbers, mainly by two numbers I say that } \\
\text { most students cannot do" (T1.o2) } \\
\text { "I think mainly, the great difficulty is their basic operations, they } \\
\text { confuse the signs of rules of multiplication or division. In } \\
\text { mathematics master who does not add up, subtract, multiply and } \\
\text { divide, how will dominate powers? how will dominate the other } \\
\text { things?" (T1.o3). } \\
\text { "Few can convert fractions to decimals, They have many } \\
\text { difficulties" (T1.o4). } \\
\text { "Students need to learn to add, subtract, multiply, are concepts and } \\
\text { procedures that have many difficulties and if they have difficulties, } \\
\text { not having the basic knowledge required, these difficulties still will } \\
\text { aggravate"(T2.o1). }\end{array}$ \\
\hline $\begin{array}{l}\text { Teaching } \\
\text { method in } \\
\text { the } 1 \text { st level } \\
\text { of education }\end{array}$ & 1 & $\begin{array}{l}\text { "Students come in different primary schools accustomed to different } \\
\text { methods, some learn through successive subtractions others by } \\
\text { adding the reverse" (T2.m1) }\end{array}$ \\
\hline
\end{tabular}




\begin{tabular}{|c|c|c|}
\hline Reasoning & 6 & $\begin{array}{l}\text { "They have to use the implicit reasoning in the division operation } \\
\text { they fail to do." (T1.r1) } \\
\text { "The difficulties appear, for example, conversions of fractions to } \\
\text { decimals" (T1.r2) } \\
\text { "Mathematics is a discipline that requires training, this is, students } \\
\text { do exercises and give up the first difficulty of the exercises. And the } \\
\text { difficulties begin to be increasing. If the student fails to follow the } \\
\text { matter in 5. grade, how will you get there ahead? The difficulties } \\
\text { are increasing and not only gets what the student learns in school." } \\
\text { (T1.r3) } \\
\text { "Can apply to real life situations and they see that is applicable for } \\
\text { them, and with these real-life situations carrying her later for more } \\
\text { complicated mathematical concepts and more difficult for them to } \\
\text { understand"(T1.r4). } \\
\text { They cannot perceive, and the difficulty of abstraction combined } \\
\text { with the lack of prerequisites to make the division is a problem that } \\
\text { cannot overcome this difficulty (T2.r1). } \\
\text { Students have a hard mental calculation, especially in multiplication } \\
\text { and division" (T2.r2). } \\
\text { "I notice that students not able to find the successive divisions and } \\
\text { do not know the multiplication table" (T2.r3). }\end{array}$ \\
\hline $\begin{array}{c}\text { Using } \\
\text { Calculator }\end{array}$ & 3 & $\begin{array}{l}\text { "The problem here is often the use of calculating machine or non- } \\
\text { use of the adding machine (T1.c1). } \\
\text { "If you have difficulties, with the use of the machine, these } \\
\text { difficulties will still worsen because they do not have why not use } \\
\text { the calculator." (T1.c2) } \\
\text { "Then they get used to using the machine and forget what they } \\
\text { previously learned" (T2.c1) }\end{array}$ \\
\hline
\end{tabular}

There appear to be a greater number of evidences in the dimension "Algorithm" and "Reasoning". However, it turns out that there is only one evidence for the dimension teaching method in the 1 st level of education. Teachers see the lack of knowledge in the algorithm as a deterrent for students to perform division operations. They point to students' "difficulty in applying the divide operation algorithm and the location of elements: divider, rest, quotient and divisor" (T2.a1), and claim that in "the division operation students have many difficulties" (T1.a3). In their view, students need to spend more time learning the algorithm, realizing that they "do not know the algorithm implementation rules and do not know decompose a number" (T1.a1). In a subject such as the Euclidean algorithm, taught in $5 .^{\circ}$ grade, teachers recommend "obliging students to do successive divisions" (T1.a2), pointing out that students have great difficulties in doing this. Students also have a lot of difficulties on "the organization of values in the process of division" (T2.a2) and on "organization of calculations" (T2.a3) when they are making the division operation.

Teachers see the lack of knowledge of basic operations as an issue that prevents the students from performing division operations. Students present "difficulties in terms of basic knowledge: addition, subtraction, multiplication and division" (T1.o1). The development of skills in the basic operations is seen as essential if the student can work with division, because "in mathematics, for students who do not master the add, subtract, multiply and divide, how will they master powers?, how will they overcome the other things?" (T1.o3). Teachers said that students had difficulties to converting a 
minute into seconds or to convert an hour into minutes. They noticed also that if they ask students to do any form of division "mainly by two numbers, most students cannot" (T1.o2). Students also have many difficulties in "converting fractions to decimals" (T1.o4). The competence of using an algorithm is compulsory according to the Portuguese educational policies, but students are not prepared or able to learn them and so difficulties rise: "if they [the students] have difficulties, not having the basic knowledge required, these difficulties still will aggravate" (T2.o1).

Only in the category "teaching method in the 1st level of education", one of the teachers pointed out that the learning division using didactic methods can leads to later difficulties when working with division. Also, the fact that students often come from "different primary schools, accustomed to different methods" (T2.m1) are also problems associated with the Tricky Topic.

Teachers understand that "the difficulty of abstraction coupled with a lack of basic knowledge" (T2.r1) presents a problem of understanding when students attempt to acquire new knowledge. The students "have to use the implicit reasoning in the division operation and they fail to do so" (T1.r1). The need for the student to remember the notion of a multiple number and know how to apply the division algorithm are factors that hinder students' ability to perform the division operation. According to the teachers, students present "difficulty in mental calculation, especially in multiplication and division" (T2.r2) and "are not able to find the successive divisions" (T2.r3). The fact that the students "do not know the multiplication tables" (T2.r3) is also a pointed problem for students unable to do a division. The discipline of Mathematics "requires training, this is, students do exercises and give up the first difficulty of the exercises. And the difficulties begin to be increasing. If the student cannot understand the content in $5 .^{\circ}$ grade, how will they move forward? The difficulties increase and not only gets what the student learns in school." (T1.r3). To improve understanding and visualization, teachers call for situations where students: "can apply maths to real life situations and develop a sound understand in context, building on this understanding to learn more complicated mathematical concepts" (T1.r4).

Teachers see the use of calculators in $5 .^{\circ}$ grade to $6 .^{\circ}$ grade as an easier alternative adopted by students to perform division. They find that the "use of calculator or nonuse of the adding machine" (T1.c1), can lead students to forget the algorithm. The students that use the calculator a lot "forget what they previously learned about the algorithm" (T2.c1). According to participant teachers, if students have difficulties and use the calculator, their understanding of the fundamental concepts in division will diminish and their ability to perform division without the aid of a calculator will get worse.

The teachers are faced with students who present a great diversity in terms of learning achieved, and who manifest different ways of thinking and learning. It is therefore increasingly necessary to implement differentiated phases with strategies tailored to the needs of each student. Thus, to see if the Tricky Topic stumbling blocks problems corresponded to those shown by their students, T2 selected a group of ten students ( 6 girls and 4 boys), from one of his classes which had the 'concept of division' as a Tricky Topic. Thus, after identifying the Stumbling Blocks associated with Tricky 
Topic, the professor created a dignostic quiz and had these students take that quiz. The teacher's radar chart contains a scale, allowing a more detailed interpretation of the quiz results.

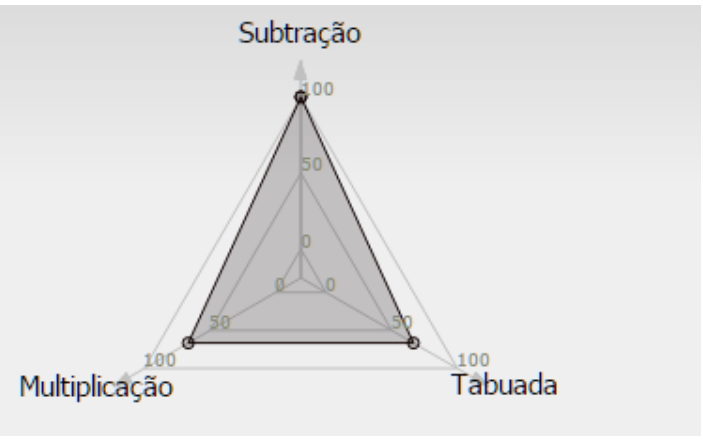

Figure 3: radar chart for student 4 in the teacher's interface (T2)

From image in Figure 11 we can see that this student answered all subtraction questions correctly, as shown by the corresponding subtraction vertex being coincident with the apex of the triangle. However, he only answered correctly on just over than half of the answers involving multiplication. This radar chart visualization suggests the student has difficulty with multiplication that may be related to his difficulty with times tables. This radar chart allows the teacher to see where the student has difficulties and adapt strategies to help him overcome the difficulties. Given that each radar chart is specific for each student, the teacher can customize teaching strategies. Another example is shown on the Figure 12.

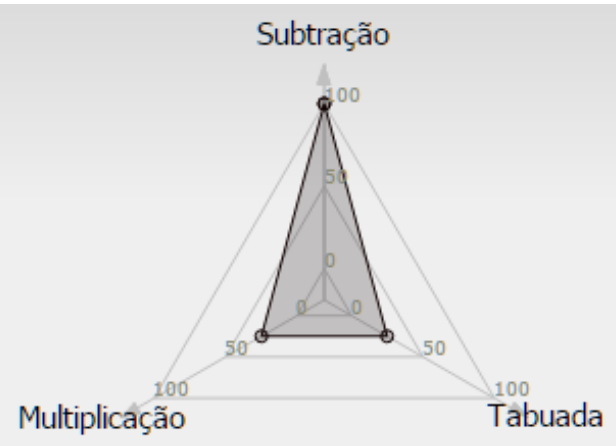

Figure 12: Radar chart after performing the diagnostic quiz - student 1

From the radar chart in figure 12, the teacher can see that the student answered correctly all questions that involved subtraction, but failed on more than half of questions that involved multiplication or knowledge of the times tables.

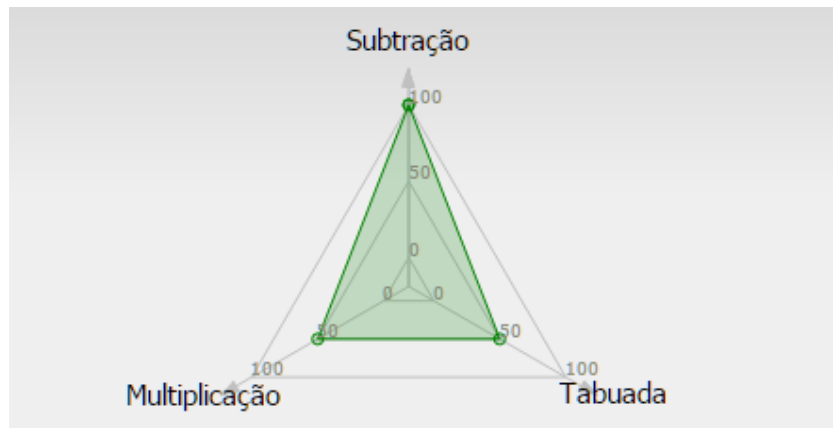


Figure 13: Radar chart after performing the diagnostic quiz - student 2

The same way, by analyzing the graphical radar chart presented in Figure 13, the teacher can see that the student answered correctly to the questions of quiz that involved subtraction operations, but answered correctly only half of the questions that involved multiplication operations or that involved the knowledge of times tables.

\section{Discussion}

Throughout the first years of school, students develop a sense of number, but it is only in their $3 \mathrm{rd}$, 4th and 5th grade that more emphasis is given to the development of skills in multiplication and division. Many students demonstrate problems in learning the division (Mendes, 2013). Understanding the implicit thinking in a division operation, from a mathematical point of view, involves knowledge of other simple operations such as addition and multiplication skills. The division and multiplication operations, although simple, reveal some complexity at cognitive level when presented in problematic situations, because the values have new meanings and the figures presented are sometimes differently exploited (Montague, 2003). One of the fundamental knowledge in the teaching of mathematics is the calculation of the four basic operations: addition, subtraction, multiplication and division. As the student develops the sense of number, she/he should be able to establish a rationale involving numbers (NCTM, 2008). By using the Tricky Topic Tool we identified together with these two teachers the concept of division as complex concept for students.

To work with the division operation at the start of the 2 nd cycle of basic education, it is assumed that students recall some concepts such as the concept of multiple of a number, the division algorithm and algebraic expressions. In general, the data collected from these teachers demonstrates the importance of student's understanding of division in order to solve problems, knowing how to use the division algorithm to keep pace with some of the topics covered in the Curricular Goals for 5th grade. Students tend to use the existing knowledge or related concepts when they learn a new concept and therefore the problems and errors made by the students tend to be systematic. Thus, when doing division students often rely on knowledge about multiplication and division that may well be wrong (Montague, 2003). This data reinforces the importance of giving students a solid understanding of this concept in the 1 st cycle.

In Portugal, the concept of division is covered for the first time in the curricular goals in the 2nd year of primary school. The concept of division is once again addressed in the $3 \mathrm{rd}$, 4th and 5th grade where other concepts will be combined relating to this operation. According to Professor T1 on the four operations addressed, "the greatest difficulties arise in the division, I'm talking about students who are in the fifth year" 
(T1). Adding that from his experience teaching in the 5th year of primary school, "90\% of students have difficulty in the division operation" (T1) and the "division of two numbers, 99\% of students can't do it" (P1). For the teachers involved in our study, sometimes the division algorithm "have difficulty in identify the elements" (T1), the dividend, the divisor, the quotient, the rest and the "organization of the elements when making the division algorithm" (T2). That is, when using the algorithm to work with the division, sometimes they "switch between the dividend the divisor" (T2). According to Professor P1 as the students not always understand the division, "they do not recognize the process of division and forget the value that is carried" (T2). The division algorithm, is a set of processes that follow the same order in similar situations (Brocardo \& Serrazina, 2008) and it's not always understood by the students.

The fact that they do not know their multiplication tables and are not able to perform a multiplication limits the students' ability to work on concepts and procedures (e.g. division) that need those auxiliary calculations. The poor performance of students not only in understanding necessary strategies, but also in using them to solve a problem leads them to give up. Therefore it is essential to teach students these important processes and strategies that help them solve the problems in a more effective and efficient way (Montague, 2003). Zhao et. al. (2012) in a study which looked at Chinese and Flemish students to know what it takes to master the four basic arithmetic operations (addition, subtraction, multiplication and division), identified that students demonstrated gaps in the four basic operations.

The division operation involves dividing a given number of equal parts. During the early years of school students learn the meaning of the division, understand the effects of dividing by integers, use and understand the notion that the division operation is the inverse operation of multiplication (NCTM, 2008). According to the results, the fact that students cannot resolve a task or problem involving a division appears to discourage students and prevent them from progressing. Also Montague (2003) states that the division operation is a mathematical procedure with some complexity and understanding division therefore involves understanding the other mathematical operations. Many children have difficulties in using the traditional division algorithm. And when the operation is necessary in mathematical problems, many students give up. Unlike the addition operation, multiplication or subtraction, the division algorithm involves the knowledge and identification of four terms dividend, divisor, quotient and rest. These terms can also cause difficulties for the students as the teachers stated in the Tricky Topic tool when they list the understanding issues that are commonly found in students. From the point of view of these teachers "the great difficulty of the students is the basic operation" (T1). To develop the competence of calculation through division operation, students need to have knowledge in terms of counting and arithmetic operations such as multiplication tables. Arguments were put forward by both teachers when identifying the difficulties that students have when performing division. They mention that students sometimes fail to "identify the elements in the division" (P2) and on the 5th year students are expected to "work with conversions and the Euclidean algorithm." (T1). According to Arends (2008), an effective teacher must in addition to other duties, be able to list a set of good practice and be able to think about the process of teaching. The mathematical knowledge of the teacher is 
essential to teach the division operation in order to be able to identify students' difficulties and realize in which algorithm stage is this difficulty (Fernandes \& Martins, 2014). The teacher plays a fundamental role so that students can understand the mathematical meaning of the division, the procedures involved in the operation, using the correct terminology and an appropriate mathematical language. By using Tricky Topic Tool we promote thinking moments on teachers around the Tricky Topic, the ability to recall moments of work between students and difficulties in the construction of knowledge about the concept of division.

Students' problems often identified by these teachers refer to difficulties in terms of successive subtraction to solve tasks associated with the division; including "not able to find the successive divisions" (T2) and "Euclidean's algorithm requires to do successive divisions." (T1). For Montague (2003) the use of additions and successive subtraction is a strategy used by children who learn division and which is based on pre-existing knowledge about addition, subtraction and multiplication. The teachers also mentioned the fact that students are not aware to the inverse relationship between multiplication and division, can also be a problem to the understanding of division operation. They also report that students usually manifest difficulty operating between numbers written in the form of fraction, because "do not realize the meaning of the elements in the fraction" (T2), have difficulty to "identify the dividend and the divisor" (T1). To suit the results obtained by Unlu and Ertekin (2012) who investigated the knowledge of a group of mathematics teachers on the division between numbers written in the form of fraction, they realized that the knowledge about the division operation with fractions does not go beyond functional knowledge. These teachers were able to apply the rules and the process inherent in the division, but were unable to explain its meaning.

Through the use of Problem Distiller tool with teachers, we realized that the understanding of essential concepts around the Tricky Topic division "sometimes it depends on a badly learned concept" (T2). Presuppose the use of "already acquired knowledge of division" (T1) as new knowledge is being developed. The lack of essential concepts, fundamental knowledge that is related to the Tricky Topic, without which the student cannot understand, was pointed out on Problem Distiller tool as one of the causes for the difficulties in the division operation. Teachers mentioned the lack of knowledge about the scientific method and the lack of support and understanding prior knowledge that the student needs to improve to understand the Tricky Topic. The lack of complementary knowledge to the division operation from the point of view of these teachers can also be a problem. They noted also that some imperfect reasoning around the division and intuitive ways of thinking about the division process can evenly become an obstacle to the understanding of division. The reflection upon the causes for the understanding of problems detected in students, allowed teachers to increase the level of awareness about the knowledge of the student.

Teaching the "division operation" not only involves knowing how to use the traditional algorithm but also understand the division operation in different situations, understand the relationship between division and multiplication and simultaneously develop a network of numerical relationships around this operation. Even the teachers who teach mathematics in the 1 st and on the 2 nd grades admit that the division is a 
difficult operation to teach to their students and their learning process is sometimes confused with the mechanization of rules associated with the algorithm instead of understanding the division operation (Mendes, 2013). The acquisition of mathematical knowledge allows us to develop reasoning, structure thinking and help future students to think and to decide. Understanding how students learn and how teachers teach mathematical concepts is of fundamental importance for the individual student progress and the organizations to which he belongs.

The Tricky Topic tool guided the teachers in the identification of the Threshold Concept and corresponding Stumbling Blocks. The Problem Distiller tool supports them in thinking through the students' difficulties, reflecting on possible causes for those difficulties, and on ways to overcome them. This was because the connections of each Tricky Topic in the Problem Distiller tool allowed teachers to divide the concept into smaller parts (the Stumbling Blocks), and establish a critical and reflective look at the teaching and learning of division operation based in the four areas identified as problematical for students: "Terminology", "Intuitive Beliefs", "Incomplete pre-knowledge" and "Complementary Concepts".

From our perspective, this process was essential to find ways to enable an effective and consolidated teaching about the tricky topic. The difficulties listed by the teachers match the data in the literature, particularly those obtained by Montague (2003), by Zhao et. al. (2012) and Fernandes and Martins (2014). Also the NCTM (2008) states that from the 3 rd to 5 th grade, students need to understand in greater depth the multiplicative nature of the number system. The results suggest that the obstacles associated with Tricky Topic identified by teachers are similar to the difficulties described in the literature about learning the division operation.

The results showed that the use of Problem Distiller prompted teachers to think outside their comfort zone. From the perception of teachers, we can say that the division operation is a Tricky Topic for the students, and the data obtained so far allow us to conclude that it is a Threshold Concept according to the criteria listed by Meyer and Land (2003). Linking the perception of teachers with the criteria listed by Meyer and Land (2003) for which a concept is a threshold, we found out upon teachers' voices:

- Can be seen as Transformative, given that by understanding the division operation students will be able to "use in everyday situations" (T2) and "to make conversions for example" (T1);

- It is Irreversible once learned is difficult to be forgotten; however teachers recognise that "the abusive use of calculator" (T1) can lead to loss of an algorithm learned in the first cycle;

- Being the division operation a key operation to for example "do successive divisions in Euclidean algorithm" (T1), to respond to "problematic situations of everyday life" (T2), it is suggested that it is Integrative;

- When the division operation is used to as the basis for understanding of other mathematical concepts. The misunderstanding in division can "compound the difficulties" (T1), because if students "do not have the necessary base 
knowledge, their difficulties in learning related concepts will increase" (T2), suggesting that the division operation may be Bounded.

- Failure to understand the concept or "confusion problems with the multiplication operation" (T2) for example may indicate that it is a Troublesome, an incorrect understanding can lead to counterintuitive relations.

\section{Conclusion}

The JuxtaLearn project created an easy to use interactive online tool called Tricky Topic Tool to help teachers identify Threshold Concepts, and a Problem Distiller Tool to help teachers uncover the reasons why their students have problems understanding Threshold Concepts. This paper described the sessions carried out with two math teachers working with these two apps. The two tools guided the work with these teachers.

The teachers found it helpful when the information they entered through the Problem Distiller was fed back to scaffold their questions construction as they constructed an online diagnostic quiz. These prompts made it easy for them to write questions that probed to reveal whether or not their students' had a deep understanding of the Tricky Topic.

The tools are easy to use so once teachers understand the process of identifying a Tricky Topic and breaking it down into its consituent stumbling blocks, which does not happen with the methods described by other studies, such as the work of Loertscher, Green, Lewis, Lin and Minderhout (2014), based on workshops, focus groups or interviews. The Tricky Topic Tool and Problem Distiller offer a fast process which can be applied to a concrete situation: an entire class, a group of students in the class, or an individual student. This allows teachers to individualize intervention and can help differentiate pedagogical strategy.

From the students' point of view, the tool allows the student to take control and manage their learning, taking control of their personalised learning pathway. The answers to the quizzes and the results as visualised in the radar chart, allow the student to understand and reflect on the difficulties that she/he has associated to that Threshold Concept, and determine for themselves what needs to be improved.

Lastly, we would like to attest that digital technology can play a significant role in transforming teaching and learning practices for teachers and students. The JuxtaLearn project recognises that teachers are always engaged in enhancing how they teach and how their students learn. An essential part of this continuous improvement in how we enable students to learn effectively must be to embed digital technology further.

Although we are huge believers in the purposeful integration of technology in classrooms to enhance teaching and learning, we must resist the temptation to think that this is the solution to solve all learning problems. Of course, the pedagogy comes first, supported by technology initiatives with a real plan for implementation and 
evaluation of effectiveness. No lack of planning is likely to result and achieve productive outcomes.

\section{Proposals for future work.}

JuxtaLearn will use the potential of 'learning analytics' to personalise the learning processes. The results of these analyses will serve several purposes, such as (1) guidance of pedagogical decisions (selection of themes and examples), (2) supervision support for teachers based on accumulated learning traces, (3) reflection support for students and teachers.

\section{Acknowledgements}

The research leading to these results has received funding from the European Community's Seventh Framework Programme under grant agreement no. 317964 JUXTALEARN. We would like to thank the interviewed teachers for their valuable collaboration.

\section{References}

1. Adams, A., Rogers, Y., Coughlan, T., Van-der-Linden, J., Clough, G., Martin, E., \& Collins, T. (2013). Teenager needs in technology enhanced learning. Workshop on Methods of Working with Teenagers in Interaction Design, CHI 2013, Paris, France.

2. Adams, A. \& Clough, G. (2015). The E-assessment burger: Supporting the Before and After in E-Assessment Systems. Interaction Design and Architecture(s) Journal - IxD\&A, N.25, 2015, pp. 39-57.

3. Arends. R. I. (2008). Aprender a ensinar. Lisboa: McGrawHill.

4. Clough, G., Adams, A., Cruz, S., Lencastre, J.A., \&Coutinho, C. (2015). I just don't understand why they don't understand: Bridging the gaps in student learning. British Journal of Educational Technology. Submitted for evaluation.

5. Bardin, L. (2013). Análise de conteúdo. Lisboa: Edições 70.

6. Barradell, S., \& Kennedy-Jones, M. (2013). Threshold concepts, student learning and curriculum: making connections between theory and practice. Innovations in Education and Teaching International, pp. 1-10.

7. Brocardo, J., \& Serrazina, L. (2008). O sentido do número no currículo de matemática. $O$ sentido do número: Reflexões que entrecruzam teoria e prática, pp. 97-115.

8. Cousin, G. (2006) An Introduction to Threshold concepts. Planet, 17, Available at http://www.sddu.leeds.ac.uk/uploaded/learning-teaching-docs/teachtalk/5-122008/cousin_threshold_concepts.pdf

9. Cruz, S., Lencastre, J.A., Coutinho, C., Clough, G., \& Adams, A. (2016). Threshold Concepts Vs. Tricky Topics - Exploring the Causes of Student's Misunderstandings with the Problem Distiller Tool. In James Uhomoibhi, Gennaro Costagliola, Susan Zvacek and Bruce M. McLaren (ed.), Proceedings of CSEDU 2016, 8th International Conference on Computer Supported Education, Volume 1, (pp. 205-215). Rome, IT: SCITEPRESS.

10. Fernandes, D. R., \&, Martins, F. M. (2014). Reflexão acerca do ensino do algoritmo da divisão inteira: proposta didática. Educação e Formação, (Vol. 9), pp.174-197.

11. Loertscher, J., Green, D., Lewis, J. E., Lin, S., \& Minderhout, V. (2014). Identification of threshold concepts for biochemistry. CBE-Life Sciences Education, 13(3), pp. 516-528.

12. Loertscher, J., Green, D., Lewis, J. E., Lin, S., \& Minderhout, V. (2014). Identification of Threshold Concepts for Biochemistry. CBE-Life Sciences Education, 13(3), pp. 516-528.

13. Machiocha, A. (2014). Teaching research methods: threshold concept. In 13th European 
conference on research methods for business and management, pp. 260-265. London.

14. Mendes, F. (2013). A aprendizagem da divisão: um olhar sobre os procedimentos usados pelos alunos. Da Investigação às Práticas, 3(2), pp. 5-30.

15. Meyer, J. \& Land, R. (2003) Threshold concepts and troublesome knowledge: linkages to ways of thinking and practising within the disciplines. In Rust, C. (Ed.) Improving student Learning - Theory and Practice Ten Years on. Oxford, Oxford Centre for Staff and Learning Development (OCSLD), pp.412-424.

16. Meyer, J. \& Land, R. (2006) Overcoming barriers to student understanding: Threshold concepts and Troublesome Knowledge. In Meyer, J. \& Land, R. (Eds.) Overcoming Barriers to Student Understanding: Threshold concepts and Toublesome Knowledge, pp.19-32. London and New York: Routledge.

17. Meyer, J. H., Knight, D. B., Callaghan, D. P., \& Baldock, T. E. (2015). An empirical exploration of metacognitive assessment activities in a third-year civil engineering hydraulics course. European Journal of Engineering Education,40(3), pp. 309-327.

18. Montague, M. (2003). Teaching Division to Students With Learning Disabilities: A Constructivist Approach, Exceptionality: A Special Education Journal, 11:3, pp. 165-175.

19. National Council of Teachers of Mathematics (2008). Princípios e Normas para a Matemática Escolar. Lisboa: APM.

20. Squire, S., \& Bryant, P. (2002a). The influence of sharing on children's initial concept of division. Journal of Experimental Child Psychology, 81, pp. 1-43.

21. Unlu, M., \& Ertekin, E. (2012). Why do pre-service teachers pose multiplication problems instead of division problems in fractions? Procedia-Social and Behavioral Sciences,46, pp. 490-494.

22. Van Someren, M. W., Barnard, Y., \& Sandberg, J. (1994). The Think Aloud Method: A Practical Guide to Modeling Cognitive Processes. London: Academic Press.

23. Zhao, N., Valcke, M., Desoete, A., Burny, E., \&Imbo, I. (2014). Differences between Flemish and Chinese primary students' mastery of basic arithmetic operations. Educational Psychology, 34(7), pp. 818-837. 